\title{
RECENSIÓN
}

\section{Díaz Fernández, Antonio M., La investigación de temas sensibles en Criminología y Seguridad. Madrid: Tecnos, 2019 (251 págs.)}

Toda disciplina académica, si busca aportar verdadero conocimiento científico, necesita de un método. Y entre todas las disciplinas académicas el método es especialmente importante para las que aún no están plenamente consolidadas. La criminología es un ejemplo de disciplina recientemente independizada de otras como la sociología, el derecho o la psicología, y que en los últimos años ha adquirido corpus propio. En ocasiones, sin embargo, las características del objeto de estudio obligan a replantear los tradicionales y validados métodos científicos, y a realizar adaptaciones para afrontarse a él. $L a$ investigación de temas sensibles en Criminología y Seguridad tiene como objetivo, precisamente, acercar esta adaptación a los estudios en criminología y seguridad. Aporta la incorporación del concepto de "sensitive topics" acuñado de manera amplia por Renzetti y Lee en 1993 para articular una obra rica tanto en temáticas, al ir más allá de las habituales de los estudios de criminología, como en matices, al huir del habitual análisis de técnicas, muestras e instrumentos.

Que el primer libro sobre temas sensibles en castellano se centre en los estudios en criminología no es casual. Más al contrario, está plenamente justificado en tanto que la criminología es, probablemente, la disciplina que concentra un mayor número de temas sensibles de estudio. De hecho, la criminología es sensible en sí misma, quizás la disciplina más sensible porque todos sus objetos de estudio - delito, delincuente, víctima y control social - hacen referencia a la parte más oscura, desviada, oculta y desagradable de la sociedad. Sin embargo, pese a que ya hace más de diez años que se reglaron los primeros estudios en criminología en la universidad española, aún no se había publicado una obra que detallara cómo conocer y profundizar en el hecho delictivo de manera no solo sistemática, sino adecuada al objeto de estudio, más allá de las breves descripciones metodológicas de artículos y algunos libros.

El libro se estructura en siete capítulos. A través de ellos, el autor se sitúa en el lugar del investigador para analizar, de una manera detallada y repleta de experiencias de otros investigadores, aspectos como la entrada en el campo, cómo configurar un rol creíble o cuáles son las medidas de protección que deben tenerse en cuenta en todo es- 
tudio de temas sensibles. Y quizás sea este último punto una de las grandes aportaciones de la obra de Díaz. A partir de la identificación de potenciales riesgos asociados a la investigación de fenómenos, por lo general, distantes social y culturalmente de los investigadores, el autor hace hincapié en la protección de los participantes y de los propios investigadores. Esta novedad se debe a que el autor, además de los más habituales riesgos físicos y metodológicos, identifica también riesgos emocionales, potencialmente presentes tanto en los participantes como en los investigadores. Para paliarlos, la obra incluye varios formularios que pueden ser empleados como guía de protocolos y consentimiento informado para los investigadores en criminología. Esta aportación es aún más relevante si se considera que los comités de ética para ciencias sociales son casi inexistentes en España.

En tiempos de prisas y premuras por publicar, la obra de Díaz es inusual. El autor reconoce que la idea se remonta a 1998, cuando comenzó su tesis doctoral sobre los servicios de inteligencia españoles y tuvo que enfrentarse al erial metodológico que suponía trabajar en estos temas. Y aunque indica que no aborda algunos temas como la violencia de género o los estudios con menores, prácticamente todo su análisis y recomendaciones son aplicables también a estos temas sensibles. Una de las riquezas de la obra es el abanico temporal de literatura que emplea, desde los años sesenta hasta nuestros días, fruto, sin duda, de esa larga maduración. Este hecho, además, permite ver la evolución de algunos temas e, incluso, cómo algunos aspectos, como la compensación a los participantes, han cambiado. Con un estilo minucioso que recuerda a las obras de Liamputtong (2007) sobre la investigación sobre vulnerables o Netnografia de Kozinets (2010), disecciona las diferentes fases y técnicas del trabajo con temas sensibles sin abrumar al lector.

Pero si hay un aspecto que reconcilia y tranquiliza al lector con respecto a sus propias investigaciones, es la descripción de cómo un investigador entra en el campo, las pruebas y roles que tiene que realizar, y las relaciones con otros participantes. Como el propio autor resalta, la metodología de las investigaciones criminológicas es generalmente descrita sin fisuras, pura y aséptica. Los artículos o libros académicos no reflejan que detrás de ella se hayan desencadenado emociones, problemas, retos, o malas experiencias con los participantes, con su entorno o con el propio investigador durante el trabajo de campo. Pero estos existen, y para aquellos investigadores que están comenzando su carrera puede ser un elemento distorsionador si previamente no han leído este libro y no han sido informados de que, a menudo, y especialmente en la investigación en criminología, el trabajo de campo es sucio, caótico y repleto de muchas más experiencias que las que se terminan trasladando al papel. Y si algo busca dejar claro el autor es que el investigador, más que una máquina aséptica que recopila e interpreta datos 
pulcros y estructurados, es una figura que aporta orden y cordura al desorden de las numerosas y heterogéneas situaciones sociales que caracterizan la vida humana —o los "cachos de humanidad", como le toma prestado a Erickson-.

Esta obra aborda una a una las diferentes técnicas que pueden emplearse para investigar temas sensibles a lo largo de las diferentes fases del trabajo de campo. Y el autor lo hace indicando las particularidades para el caso concreto de los estudios en criminología y seguridad, huyendo — como anuncia en la Introducción — de reproducir alguno de los cientos de manuales que existen sobre cómo investigar. Recuerda, de alguna forma, a la Escuela de Chicago, al abordar temas desde un enfoque muy práctico. Es así de valorar la explicación detallada de las experiencias de numerosos investigadores, que sostiene en una rica bibliografía que ocupa cuarenta páginas. A partir de ella, nos acerca a temáticas y a técnicas que son empleadas desde la antropología hasta los estudios de enfermería, por ejemplo, en el trabajo de gestión emocional o estimación de muestras de poblaciones ocultas. De esta forma, aspectos que suelen ser mínimamente detallados en los artículos académicos o libros, como la grabación de las entrevistas, la posible compensación económica de los participantes y la influencia del lugar en el trabajo de campo, son ampliamente abordados en esta obra. El autor los detalla con ejemplos de estudios de diferentes países, de forma que el lector puede, siguiendo estos ejemplos, conocer una pluralidad de opciones para cuestiones tales como el mejor tipo de compensación para un participante — no siempre la económica — o el mejor lugar para realizar una entrevista.

Por su singularidad, destaca el tratamiento que realiza de la observación encubierta. Esta técnica es justificada por algunos autores en situaciones en las que el acceso al campo es difícil. En general, en criminología, las dificultades para acceder al campo aparecen constantemente, ya que sus entornos propios de la investigación, al estar relacionados con el crimen, la victimización o con organizaciones de seguridad no suelen aceptar la presencia de un investigador externo. Díaz, apoyándose en ejemplos extraídos de diferentes investigaciones, intenta delimitar las posibilidades de esta técnica, aceptada por algunas investigaciones y grandes universidades, aunque con claras restricciones, y siempre que esté justificada su necesidad, quién conocerá que se está llevando dicha investigación y qué es exactamente lo que se pretende investigar. Esto es de gran utilidad en criminología, donde no son pocos los insiders (policías, funcionarios de prisiones, trabajadores sociales...) que acaban realizando investigaciones sobre el lugar donde trabajan, con la gran confusión que les puede generar la dualidad de ser uno de ellos y a la vez tratar de extraer datos de forma objetiva.

La obra de Antonio Díaz presta una especial atención a la protección emocional de los investigadores y aporta, de manera innovadora para la literatura en castellano, cómo 
se ha de garantizar la protección de los transcriptores y el equipo de apoyo a los investigadores. Estas personas - en no pocas ocasiones estudiantes o investigadores en formación - se encargan de transcribir y categorizar las experiencias de otros. Este proceso incluye la valoración crítica de las experiencias de otras personas y la transcripción de audios o vídeos, lo que les transporta, en alguna medida, al propio trabajo de campo. Y, pese a la gran relevancia de esta labor, se realiza casi siempre sin formación específica. Por esta razón se han detectado casos de "traumatización vicaria" entre investigadores, mostrando la necesidad de que estos sean también incorporados a un proceso de formación y acreditación ética y emocional previo al trabajo con los datos. La obra también recoge una serie de protocolos y recomendaciones a los investigadores, basadas en las experiencias de otros, para evitar la "traumatización vicaria"; entre ellas se encuentran recomendaciones sencillas como no transcribir entrevistas tras la caída del sol, no entrevistar a más de una persona al día o hacer algo de deporte tras el trabajo de campo, y otras más complejas.

Estamos, en definitiva, ante un libro original y pionero en la literatura académica y metodológica en castellano. Alejándose de los tradicionales libros metodológicos que abordan de manera descontextualizada técnicas e instrumentos, Díaz concibe y diseña una obra con un enfoque claramente aplicado y comprensible para los investigadores en criminología y seguridad. Este eje común le aporta una gran coherencia interna repleta de experiencias de otros investigadores en temas tan amplios como las pandillas juveniles, el trabajo en centros de reclusión, los sintecho o los inmigrantes irregulares. Por estas razones considero que la obra del profesor Antonio Díaz marca un antes y un después en la investigación criminológica en España. Aporta un marco teórico y un instrumental metodológico a una disciplina aún en crecimiento, abarcando todas las etapas que van desde el diseño de una investigación hasta el momento en que el investigador abandona el campo. Y, al hacerlo, cumple con el objetivo más alto al que cualquier trabajo académico puede aspirar: el de contribuir a elevar la calidad de la investigación de su disciplina.

Cristina del Real Castrillo

Universidad de Cádiz, Cádiz, España cristina.delreal@uca.es 